\title{
Backwater controls of avulsion location on deltas
}

\author{
Phairot Chatanantavet, ${ }^{1}$ Michael P. Lamb, ${ }^{1}$ and Jeffrey A. Nittrouer ${ }^{2}$ \\ Received 2 November 2011; revised 30 November 2011; accepted 3 December 2011; published 12 January 2012.
}

[1] River delta complexes are built in part through repeated river-channel avulsions, which often occur about a persistent spatial node creating delta lobes that form a fan-like morphology. Predicting the location of avulsions is poorly understood, but it is essential for wetland restoration, hazard mitigation, reservoir characterization, and delta morphodynamics. Following previous work, we show that the upstream distance from the river mouth where avulsions occur is coincident with the backwater length, i.e., the upstream extent of river flow that is affected by hydrodynamic processes in the receiving basin. To explain this observation we formulate a fluvial morphodynamic model that is coupled to an offshore spreading river plume and subject it to a range of river discharges. Results show that avulsion is less likely in the downstream portion of the backwater zone because, during high-flow events, the water surface is drawn down near the river mouth to match that of the offshore plume, resulting in river-bed scour and a reduced likelihood of overbank flow. Furthermore, during low-discharge events, flow deceleration near the upstream extent of backwater causes enhanced deposition locally and a reduced channel-fill timescale there. Both mechanisms favor preferential avulsion in the upstream part of the backwater zone. These dynamics are fundamentally due to variable river discharges and a coupled offshore river plume, with implications for predicting delta response to climate and sea level change, and fluvio-deltaic stratigraphy. Citation: Chatanantavet, P., M. P. Lamb, and J. A. Nittrouer (2012), Backwater controls of avulsion location on deltas, Geophys. Res. Lett., 39, L01402, doi:10.1029/2011GL050197.

\section{Introduction}

[2] Avulsion of rivers near their mouths is one of the main processes that control coastal deposition patterns including land building, delta morphology, and sedimentary basin stratigraphy [e.g., Mackey and Bridge, 1995; Slingerland and Smith, 2004]. Moreover, much of the world's population lives near deltas, areas subject to catastrophic flooding as a result of river avulsion [e.g., Syvitski et al., 2005; Paola et al., 2011]. In light of rising sea level, we need mechanistic models that predict the location of river avulsions to mitigate future hazards and guide wetland restoration efforts.

[3] The necessary conditions for river avulsion have been the subject of ongoing debate [e.g., Bryant et al., 1995; Reitz et al., 2010]. Most workers have focused on controls on avulsion frequency [e.g., Törnqvist et al., 1996; Jerolmack and Mohrig, 2007] and the effect of avulsion on stratigraphic

\footnotetext{
${ }^{1}$ Division of Geological and Planetary Sciences, California Institute of Technology, Pasadena, California, USA.

${ }^{2}$ Department of Geology, University of Illinois at Urbana-Champaign, Urbana, Illinois, USA.

Copyright 2012 by the American Geophysical Union. 0094-8276/12/2011GL050197
}

architecture [e.g., Mackey and Bridge, 1995]. For example, using data from the rock record, laboratory experiments, and modern rivers, Mohrig et al. [2000] and Jerolmack and Mohrig [2007] found that the characteristic timescale for avulsion (i.e., the reciprocal of avulsion frequency), $T_{A}$, is proportional to the time needed to fill one channel depth with sediment, $T_{h}=h_{c} / v_{A}$, where $h_{c}$ is a characteristic flow depth and $v_{A}$ is vertical aggradation rate.

[4] There has been less work on the controls on avulsion location, which sets the fundamental length scale of deltas [e.g., Jerolmack, 2009]. Many deltaic rivers tend to avulse at a distance, $L_{A}$, upstream from the shoreline (i.e., $x=L_{A}$, where $x$ is the distance along river upstream of the shoreline) with each successive avulsion creating a new depositional lobe that fans out from the avulsion node [e.g., Slingerland and Smith, 2004]. Edmonds et al. [2009] showed in experiments that avulsions tend to occur at locations with persistent overbank flow caused by bed aggradation. Jerolmack and Swenson [2007] showed that $L_{A}$ scales roughly with a characteristic backwater length, $L_{b}$, which is the upstream distance over which river hydraulics are affected by the receiving ocean or lake basin [e.g., Chow, 1959] and is typically approximated by $L_{b} \approx h_{c} / S$, where $S$ is the channel bed slope [e.g., Paola, 2000]. Nittrouer et al. [2012a] showed that Mississippi River deposition rates are enhanced in the upstream part of the backwater zone, a region coincident with four major avulsions during the Holocene. Our own compilation of the avulsion length scale for different river deltas confirms these observations (Figure 1; see auxiliary material (Text S1, section S1)). Herein we offer an explanation for the observation that the avulsion length scale correlates with the backwater length (i.e., $L_{A} \propto L_{b}$ ) using a quasi-2D morphodynamic model of a coupled river and river plume system subject to a range of water discharges.

\section{Model Goal and Formulation}

[5] The avulsion process is complex and a complete model for avulsion location may need to include dynamics at both geomorphic (e.g., levee and delta morphodynamics) and flood (e.g., sediment transport and levee breaching) timescales [e.g., Slingerland and Smith, 2004; Edmonds et al., 2009]. Herein we aim to test two potential controls on the locus of avulsion on deltas that span this range in timescales. First, we hypothesize that the characteristic time for channel filling (which scales with the avulsion timescale, i.e., $T_{A} \propto T_{h}$ [Mohrig et al., 2000; Jerolmack and Mohrig, 2007]) is spatially variable and is minimized at $x \approx L_{b}$ due to the effect of backwater hydrodynamics on river channel depth and bed aggradation. Second, we hypothesize that the capacity of a channel to contain flood water and therefore mitigate levee

\footnotetext{
${ }^{1}$ Auxiliary materials are available in the HTML. doi:10.1029/ 2011 GL050197.
} 


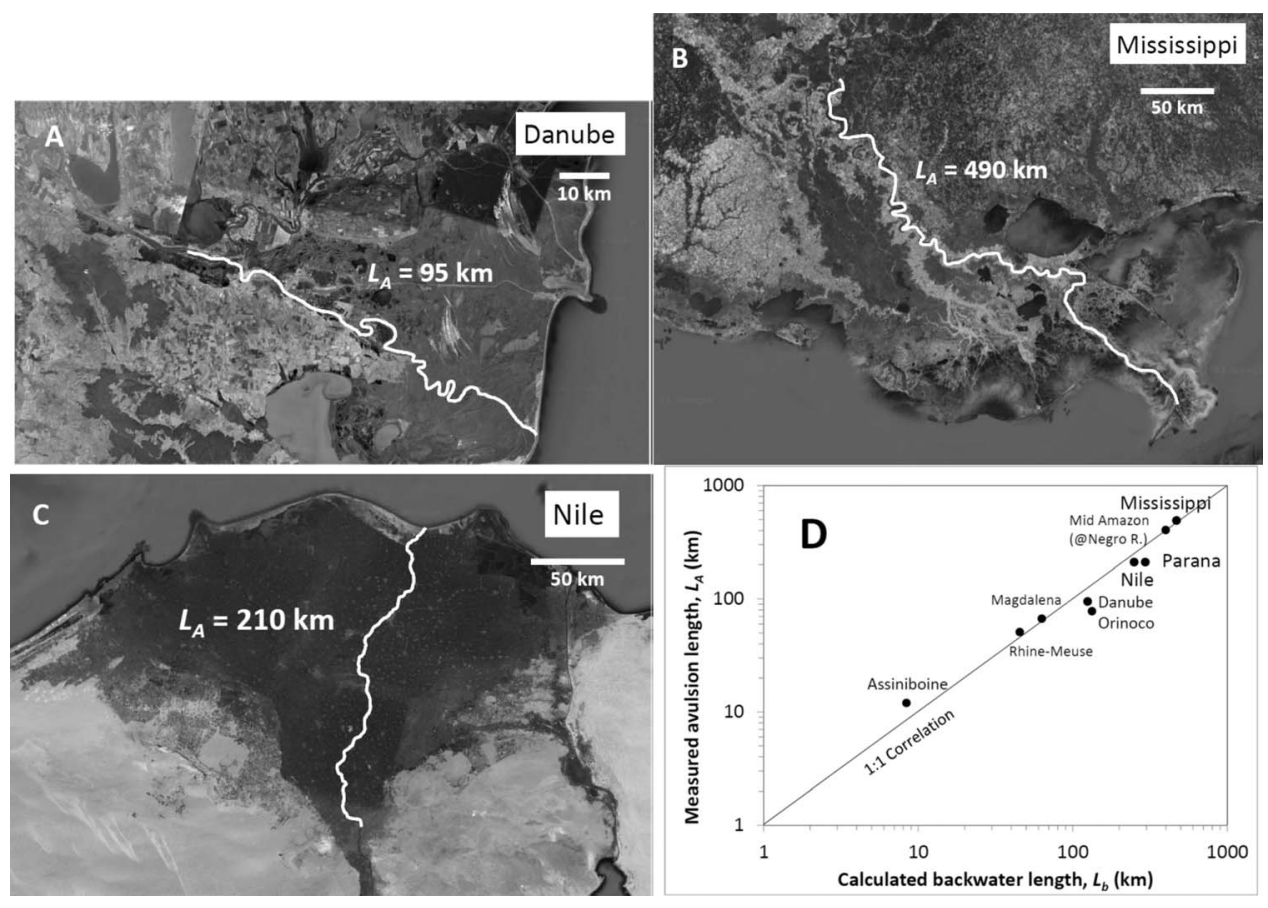

Figure 1. (a-c) Aerial photos showing an avulsion length $\left(L_{A}\right)$ for three deltaic rivers. (d) Backwater length scale, $L_{b}$, versus the measured avulsion length scale, $L_{A}$, for nine deltaic rivers.

breaks is spatially variable and increases near the river mouth due to drawdown of the river water surface to match the water depth in the receiving basin [e.g., Lane, 1957]. We quantify the second effect using the water depth during a flood event, $h$, normalized by the normal-flow water depth (i.e., the depth upstream of the backwater zone) for a 2-year recurrence interval flood event, $h_{c}$.

[6] To test our hypotheses quantitatively, we formulate a mechanistic model for a coupled river and river plume. Most previous models for fluvio-deltaic evolution neglect backwater dynamics either by assuming uniform flow [e.g., Flemings and Jordan, 1989; Swenson et al., 2005] or a single characteristic river discharge [e.g., Parker et al., 2008], which prevents the backwater zone from being dynamic [Lamb et al., 2012]. Herein, we solve the 1-D non-uniform shallow-water flow equations for conservation of fluid mass and momentum [Chow, 1959] (auxiliary material (Text S1, section S2)). We treat the offshore plume as a depthaveraged, steady, homopycnal current, where momentum is balanced in 1-D between a hydrostatic pressure gradient and drag along the bed. We neglect drag and entrainment along the lateral margins of the plume and represent lateral spreading of the plume geometrically by assigning a set spreading angle of $5.7^{\circ}$ beyond the shoreline $(x<0)$, consistent with theory, experiments, and field observations of planar turbulent jets [e.g., Wright and Coleman, 1971; Rajaratnam, 1976; Rowland et al., 2010]. Lamb et al. [2012] found that backwater dynamics are insensitive to plume spreading for spreading angles greater than $\sim 1^{\circ}$, which is sufficient to render the water-surface elevation at the river mouth relatively insensitive to changes in river discharge as compared to farther upstream. Our model couples these hydrodynamic equations with a semi-empirical transport formula for bed-material load transport and sediment mass conservation that accounts for bed aggradation and degradation (auxiliary material (Text S1, section S2)).

[7] Our goal is to model backwater effects on avulsion over geomorphic timescales as generically as possible, which necessarily neglects the full complexity of a given river (e.g., meandering, overbank flow and bifurcations). Nonetheless, to explore the model results it is useful to use input parameters that scale roughly after a natural river. Here the lower Mississippi River, USA, (auxiliary material, Text S1). is used because it is a large lowland river where backwater and sediment dynamics have been investigated [e.g., Lane, 1957; Karadogan et al., 2009; Nittrouer et al., 2011]. Model simulations were focused on the lower $700 \mathrm{~km}$ of the Mississippi River because this incorporates the backwater zone $(x<\sim 500 \mathrm{~km})$ and a comparative region upstream; however, we neglect tributaries and distributaries for simplicity. Model simulations were run for 1500 years, which is the approximate characteristic timescale for avulsion on the Mississippi Delta [e.g., Coleman, 1988].

[8] Three model simulations are presented. For the first case we show results for a constant inflow discharge, a common assumption in fluvial morphodynamic models [e.g., Paola et al., 1992], which does not produce a strong preferential avulsion zone. Second, we show how variable flood discharges force a dynamic backwater zone and may control the avulsion length scale over flood and geomorphic timescales. Third, we show how relative sea-level rise affects the preferential zone for avulsion.

\section{Results}

[9] For the case of constant river discharge, we set $Q_{w}=$ $2.9 \times 10^{4} \mathrm{~m}^{3} / \mathrm{s}$, which has a 2-year peak-annual-flood recurrence on the Mississippi River and allow the channel to evolve for 1500 yrs. We define the characteristic channel 
depth $\left(h_{c}\right)$ as the normal flow depth for $Q_{w}=2.9 \times 10^{4} \mathrm{~m}^{3} / \mathrm{s}$ at $x=700 \mathrm{~km}$ (i.e., far upstream of backwater effects). Model simulations show the expected result that spatial patterns of erosion and deposition shape channel morphology toward a graded state, where deposition occurs only in response to delta progradation [e.g., Muto and Swenson, 2006] (Figure 2a). The water depth in the channel is approximately uniform thereby creating a nearly equal likelihood of levee breaching everywhere (Figure 3a). Likewise, the time to aggrade one channel depth, $T_{h}$, gradually decreases downstream and shows no preferential avulsion location at $x \approx L_{b}$ (Figure 3b). For this case, the offshore plume has little effect on fluvial morphodynamics, except at the river mouth where spreading forces deposition (Figure 2a).

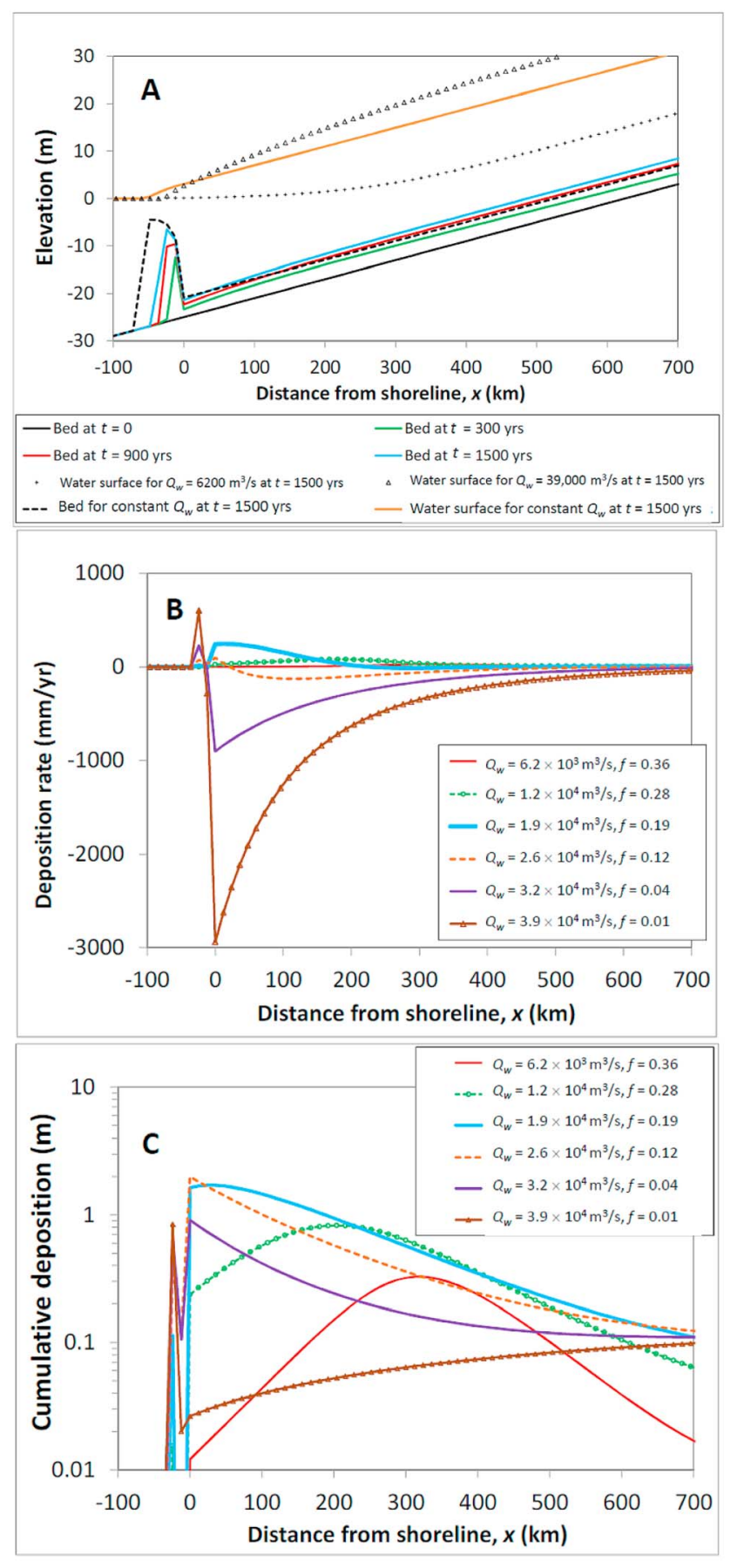

[10] To explore the effect of variable discharges, we linearly divided the last 88 years of observed daily discharge on the lower Mississippi River (Tarbert Landing, MS; U.S. Army Corps of Engineers) into six bins (Figure $2 b$ and auxiliary material (Text S1, section S2)). In the simulation, a complete cycle of these six discharge events was run (from lowest to highest discharge) for a period of 30 years, which corresponds to the peak-annual-flood recurrence interval of the largest flood event considered $\left(Q_{w}=3.9 \times 10^{4} \mathrm{~m}^{3} / \mathrm{s}\right)$. This cycle was repeated to reach $T_{A}=1500$ years of total run time. A sensitivity analysis revealed using the six discharge bins was sufficient to capture the model dynamics (i.e., further sub-divisions did not significantly change model results) and that model results are insensitive to the order in which the discharge-events occur.

[11] In contrast to the case of steady discharge, variable discharge combined with the spreading offshore river plume results in distinctly different model results. Even after 1500 years the model predicts a backwater zone for low discharges that extends from the shoreline to $\sim 400 \mathrm{~km}$ upstream (Figure 2a). The backwater zone shows a characteristic downstream increase in water depth because the water depth at the shoreline is greater than the normal flow depth (i.e., M1 profile; [Chow, 1959]). This creates a zone of spatial deceleration and deposition (Figures $2 \mathrm{~b}$ and $2 \mathrm{c}$ ). For $Q_{w}<2 \times 10^{4} \mathrm{~m}^{3} / \mathrm{s}$, as discharge is increased the maximum rate in deposition rate shifts downstream and increases in magnitude. Because the river plume is allowed to spread, the water surface elevation for $x<0$ is relatively insensitive to discharge as compared to farther upstream [e.g., Lane, 1957] and is very near sea level, consistent with stage-height measurements that show $<1 \mathrm{~m}$ variation near $x=0$ [e.g., Karadogan et al., 2009]. For high discharges $\left(Q_{w}>3 \mathrm{x}\right.$ $10^{4} \mathrm{~m}^{3} / \mathrm{s}$ ), this results in a water depth at the shoreline that is smaller than the normal-flow depth, which creates a drawdown zone characterized by spatial acceleration and scour [Lamb et al., 2012] (Figure 2). For the high discharge events, deposition only occurs for $x<0$ where plume spreading

Figure 2. (a) Modeled bed and water surface elevation for the case of the lower Mississippi River with $\sigma=0$. Results are shown for a variable-discharge model including the bed topography at four times during the model run $(t=0,300$, 900 , and 1500 years) and the water surface topography for the minimum and maximum discharges at $t=1500$ years. Also shown are bed and water surface results for a model run with a constant water discharge of $Q_{w}=2.9 \times 10^{4} \mathrm{~m}^{3} / \mathrm{s}$ after $t=1500$ years. (b) Modeled deposition rates for the variable discharge model. Negative values indicate erosion. The variable discharge model consists of six discharge events that were run for a set fraction $(f)$ of a 30-year period, equivalent to model run time of $t=600$ to 630 years in Figure 2a, corresponding to their frequency of occurrence observed for the Mississippi River. The complete 30-year cycle was repeated during the model run shown in Figure 2a. (c) Cumulative deposition amount for the six discharge events in Figure $2 \mathrm{~b}$ which shows the progressive state of the bed following each successive flow event that were run in order from low to high discharge. The cumulative deposition amount is always positive because deposition during low discharge events (which were run first) more than compensates for erosion during high discharge events. 

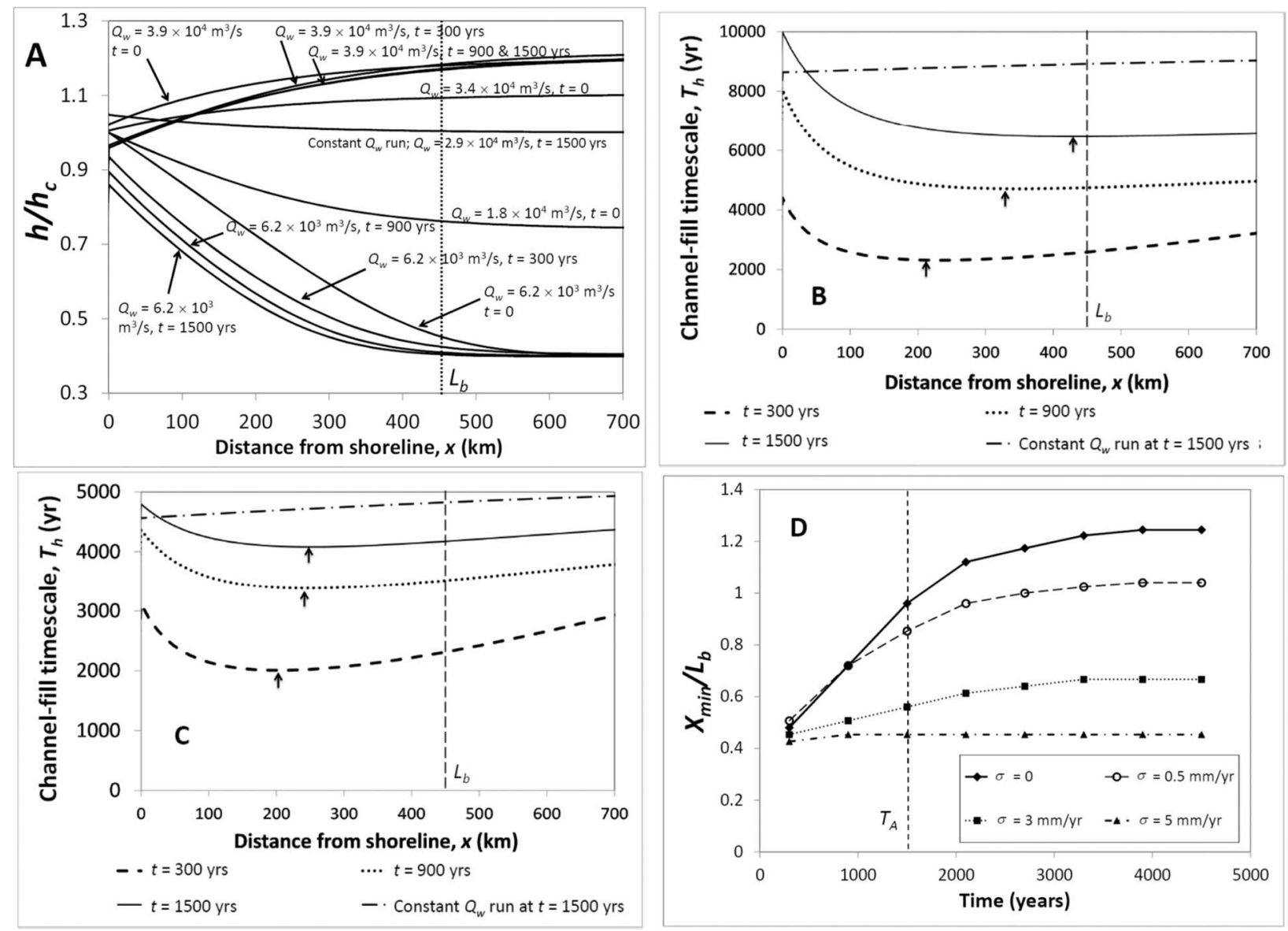

Figure 3. (a) Modeled water depth $(h)$ normalized by the characteristic upstream flow depth $\left(h_{c}\right)$ as a function of distance from the shoreline for the case of the Mississippi River with $\sigma=0$. The lines marked "Constant $Q_{w}$ run" are the model case with a constant characteristic discharge (2-year flood). The remaining lines show predictions for the model run with variable discharges $\left(Q_{w}\right)$ at different model run times $(t)$. (b) Model results for channel-fill timescale $\left(T_{h}=h_{c} / v_{A}\right)$ as a function of distance from the shoreline for the case with no base level rise $(\sigma=0)$ and (c) $\sigma=3 \mathrm{~mm} / \mathrm{yr}$. Arrows indicate the locations of minimum channel-fill time $\left(X_{\mathrm{min}}\right)$, which suggest a preferential avulsion zone. Results from the variable discharge case are shown at various run times, whereas results from the constant discharge case are shown for $t=1500$ years. (d) $X_{\min }$ normalized by the calculated backwater length $\left(L_{b}\right)$ as a function of time for different rates of base level rise $(\sigma)$.

forces spatial deceleration. Over many discharge cycles, topography evolves to the suite of discharges such that deposition during low flow is nearly compensated for by erosion during high flow events (Figure 2c), resulting in net aggradation. The net aggradation rate is controlled in part by hydrodynamic feedbacks with the aggrading and prograding delta $(x<0$; Figure 2a) [e.g., Muto, 2001].

[12] The result of coupling the river to an offshore spreading plume under a range of discharges is a persistent backwater zone that shows deposition at low flows and erosion at high flow, which is consistent with observations from the modern Mississippi River [Nittrouer et al., 2011; Lamb et al., 2012; Nittrouer et al., 2012a]. This has a significant effect on the avulsion length scale metrics. Avulsions occur during floods when rivers are most likely to break or overtop their levees [e.g., Slingerland and Smith, 2004; Edmonds et al., 2009]. Model results show that the flow depth during large flood events is relatively insensitive to discharge for $x<L_{b}$ due to water-surface drawdown (Figure 3a). In this region, higher discharges are accommodated by increasing the water surface slope rather than increasing the water depth, the latter of which dominates upstream of the backwater zone [Nittrouer et al., 2012b]. This produces a diminished normalized water depth $\left(h / h_{c}\right)$ for $x<L_{b}$, and therefore less likelihood for river avulsion within that zone.

[13] In addition to inducing spatial changes in normalized river depth during high magnitude flood events, backwater dynamics affect the characteristic timescale for channel aggradation, $T_{h}$. For the variable discharge case, $T_{h}$ increases in time everywhere because the net aggradation rate, $v_{A}$, decreases as the channel bed approaches a quasi-steady state (Figure 3b). Due to the persistent backwater zone, deposition rates for low-flow events tend to be greatest within the upstream end of the backwater zone owing to deceleration caused by spatial divergence of the bed and water surface. Furthermore, high discharge events tend to focus scour within the downstream portion of the backwater zone $(x<$ $0.5 L_{b}$ ), which lowers net aggradation rates and increases the channel depth (Figures $2 b$ and $2 c$ ), making avulsion less likely there (Figure $3 \mathrm{~b}$ ). The combined effect is a channel-fill timescale $\left(T_{h}=h_{c} / v_{A}\right)$ that has a minimum at about $x=X_{\min }=$ $0.5 L_{b}$ after 300 years of model simulation (Figure $3 \mathrm{~b}$ ). The minimum in $T_{h}$ becomes less pronounced in time and its 
location is approximately steady at $X_{\min } \approx 1.2 L_{b}$ for $t \geq 1500$ years (Figure $3 \mathrm{~d}$ ). These results are in strong contrast to the constant discharge case which shows near constant $T_{h}$ and no preferred avulsion location (Figure 3b).

[14] To investigate the effect of base level (e.g., due to subsidence or eustatic sea-level rise) on the avulsion length scale, we followed the same procedure as in variable discharge case above but also explored a range of steady, uniform rates of base level rise, $\sigma$. For the Mississippi Delta, the magnitudes of base level rise are highly debated and estimates for the Holocene range from $\sigma=0.5-5 \mathrm{~mm} / \mathrm{yr}$ [e.g., Blum and Roberts, 2009; Kim et al., 2009]. Base level rise has little effect on the predicted water surface elevation over flood timescales, but it affects the spatial patterns of erosion and deposition over longer timescales (Figure 3c). Greater $\sigma$ increases deposition rates everywhere which causes smaller $T_{h}$ as compared to the case with $\sigma=0$. Furthermore, greater $\sigma$ increases deposition rates preferentially near the upstream boundary of the backwater zone which accentuates the minimum in $T_{h}$ and outlines a persistent zone of preferential avulsion (i.e., $X_{\min } \approx 0.6 L_{b}$ for the case of $\sigma=3 \mathrm{~mm} / \mathrm{yr}$ ) (Figure $3 \mathrm{c}$ ). Higher subsidence rates tend to lower $T_{h}$, accentuate the minimum in $T_{h}$, and shift $X_{\min }$ towards the river mouth (Figures $3 b-3 d$ ).

\section{Discussion}

[15] Our model predicts a channel-fill timescale of $T_{h} \sim$ 6500 yrs for the Mississippi River after 1500 years of run time for the case of $\sigma=0$ (Figure 3b). This, however, is inconsistent with observations that the avulsion timescale for the Mississippi River is $T_{A} \sim 1500$ years [e.g., Coleman, 1988]. The inclusion of base level rise in our model increases the predicted deposition rates (i.e., from $\sim 4 \mathrm{~mm} / \mathrm{yr}$ to $\sim 5 \mathrm{~mm} / \mathrm{yr}$ in the case $\sigma=3 \mathrm{~mm} / \mathrm{yr}$ ), which in turn decreases $T_{h}$ to values that are more similar to the measured $T_{A}$ (Figure 3c). This notwithstanding, a scaling ratio of unity between $T_{h}$ and $T_{A}$ may not be expected. As noted by Jerolmack [2009], $T_{h}>T_{A}$ for many large rivers and this might be because the height of levees with respect to the neighboring floodplain (i.e., superelevation height, $\Delta z$ ) is a more appropriate length scale for predicting avulsion frequency than the channel depth. For the lower Mississippi River, the inter-avulsion superelevation height is about $5 \mathrm{~m}$ [e.g., Törnqvist et al., 1996], which if used in place of channel depth would reduce our predicted avulsion timescales (i.e., $T_{h}=\Delta z / v_{A}$ ) by about a factor of five, but would not affect our predictions of avulsion location.

[16] Our model simulations show a zone of drawdown during high flow events and backwater during low flow events, which result in lower flood stages near the river mouth as compared to farther upstream (Figure 3a) and a minimum in the channel-fill timescale upstream of the river mouth (Figures 3b-3d). Both of these effects should lead to a zone of preferential avulsion some distance upstream from the river mouth that scales with the backwater length. Following Bresse [1860], Lamb et al. [2012] showed that for highly subcritical flows $(F r \ll 1$, where $F r$ is the Froude number), the maximum upstream length influenced by drawdown is $0.5 h_{n} / S$ where $h_{n}$ is normal flow depth, whereas the maximum extent of backwater at low flows is $h_{s} / S$ where $h_{s}$ is the depth at the shoreline. Because avulsions are one of the main controls on delta evolution, these scaling relationships explain why delta lobes are more extensive in deep, low gradient rivers (e.g., Figure 1), and they provide a means for estimating delta response to perturbations that affect flow depth, channel depth at the shoreline, and channel slope (e.g., climate-induced changes in river discharge, sea level or sediment supply) [e.g., Jerolmack, 2009]. These scaling relationships may also be useful for reconstructing ancient fluvio-deltaic systems from stratigraphy on Earth and Mars [e.g., Paola, 2000]; for example, by allowing estimation of river-channel dimensions from observations of the size of delta lobes and channel slope.

\section{Conclusions}

[17] To explain the observation that river avulsions on deltas tend to occur at the upstream extent of the backwater zone, we performed a numerical simulation of a coupled river and river plume system subject to variable flow discharges. Results show that there is an exclusion zone, where avulsion is less likely than other locations, that persists throughout the inter-avulsion time period for the Mississippi River $\left(\sim 10^{3}\right.$ years $)$ and that corresponds roughly to half the backwater length (i.e., $x<0.5 L_{b}$ ). Within this zone, relative flood stage heights (i.e., $h / h_{c}$ ) are diminished and the deposition timescales to fill a channel (i.e., $h_{c} / v_{A}$ ) are large; both metrics indicate that avulsion is less likely in the downstream portion of the backwater zone. Moreover, the channel fill timescale shows a minimum in the upstream portion of the backwater zone due to preferential deposition there, resulting in a predicted heightened frequency of avulsions. This preferential zone for avulsion exists because variable flood discharges result in backwater hydrodynamics at low flows and drawdown hydrodynamics at high flows, which in turn create spatial variations in deposition patterns and flow depths. These dynamics do not exist for simulations with constant river discharge, which suggests that variable discharges and an offshore spreading plume may be needed to accurately simulate fluvio-deltaic morphodynamics.

[18] Acknowledgments. Acknowledgement is made to the donors of the American Chemical Society Petroleum Research fund and to Caltech for support of this work. J. Nittrouer wishes to thank the NSF Postdoctoral Fellowship (EAR0948224) for his financial support. We thank David Mohrig for insightful discussion as well as Doug Edmonds and Doug Jerolmack for formal reviews that helped strengthen the final manuscript.

[19] The Editor thanks Douglas Edmonds and Douglas Jerolmack for their assistance in evaluating this paper.

\section{References}

Blum, M. D., and H. H. Roberts (2009), Drowning of the Mississippi delta due to insufficient sediment supply and global sea-level rise, Nat. Geosci., 2, 488-491, doi:10.1038/ngeo553.

Bresse, J. A. C. (1860), Cours de Mécanique Appliquée: Professé a l'École Imperiale des Ponts et Chaussées. Seconde Partie, Hydraulique, 370 pp., Gauthier-Villars, Paris, France.

Bryant, M., P. Falk, and C. Paola (1995), Experimental study of avulsion frequency and rate of deposition, Geology, 23(4), 365-368, doi:10.1130/ 0091-7613(1995)023<0365:ESOAFA>2.3.CO;2.

Chow, V. T. (1959), Open Channel Hydraulics, 680 pp., McGraw Hill, New York.

Coleman, J. M. (1988), Dynamic changes and processes in the Mississippi River delta, Geol. Soc. Am. Bull., 100(7), 999-1015, doi:10.1130/00167606(1988)100<0999:DCAPIT>2.3.CO;2

Edmonds, D. A., D. Hoyal, B. A. Sheets, and R. L. Slingerland (2009), Predicting delta avulsions: Implications for coastal wetland restoration, Geology, 37(8), 759-762, doi:10.1130/G25743A.1.

Flemings, P. B., and T. E. Jordan (1989), A synthetic stratigraphic model of foreland basin development, J. Geophys. Res., 94(B4), 3851-3866, doi:10.1029/JB094iB04p03851. 
Jerolmack, D. J. (2009), Conceptual framework for assessing the response of delta channel networks to Holocene sea level rise, Quat. Sci. Rev., 28(17-18), 1786-1800, doi:10.1016/j.quascirev.2009.02.015.

Jerolmack, D. J., and D. Mohrig (2007), Conditions for branching in depositional rivers, Geology, 35(5), 463-466, doi:10.1130/G23308A.1.

Jerolmack, D. J., and J. B. Swenson (2007), Scaling relationships and evolution of distributary networks on wave-influenced deltas, Geophys. Res. Lett., 34, L23402, doi:10.1029/2007GL031823.

Karadogan, E., C. S. Willson, and C. R. Berger (2009), Numerical modeling of the Lower Mississippi River-Influence of forcings on flow distribution and impact of sea level rise on the system, paper presented at Oceans 2009: Marine Technology for Our Future: Global and Local Challenges, Inst. of Electr. and Electron. Eng., Biloxi, Miss.

Kim, W., D. Mohrig, R. Twilley, C. Paola, and G. Parker (2009), Is it feasible to build new land in the Mississippi River delta?, Eos Trans. $A G U$, 90(42), 373, doi:10.1029/2009EO420001.

Lamb, M. P., J. A. Nittrouer, D. Mohrig, and J. Shaw (2012), Backwater and river-plume controls on scour upstream of river mouths: Implications for fluvio-deltaic morphodynamics, J. Geophys. Res., doi:10.1029/ 2011JF002079, in press.

Lane, E. W. (1957), A study of the shape of channels formed by natural streams flowing in erodible material, 170 pp., Missouri River Div., U.S. Army Corps of Eng., Omaha, Nebr.

Mackey, S. D., and J. S. Bridge (1995), 3-dimensional model of alluvial stratigraphy-Theory and application, J. Sediment. Res., Sect. B, 65(1), $7-31$.

Mohrig, D., P. L. Heller, C. Paola, and W. J. Lyons (2000), Interpreting avulsion process from ancient alluvial sequences: Guadalope-Matarranya system (northern Spain) and Wasatch Formation (western Colorado), Geol. Soc. Am. Bull., 112(12), 1787-1803, doi:10.1130/0016-7606 (2000) $112<1787$ :IAPFAA $>2.0 . \mathrm{CO} ; 2$.

Muto, T. (2001), Shoreline autoretreat substantiated in flume experiments, J. Sediment. Res., 71(2), 246-254, doi:10.1306/091400710246.

Muto, T., and J. B. Swenson (2006), Autogenic attainment of large-scale alluvial grade with steady sea-level fall: An analog tank-flume experiment, Geology, 34(3), 161-164, doi:10.1130/G21923.1.

Nittrouer, J. A., D. Mohrig, M. A. Allison, and A. P. B. Peyret (2011), The Lowermost Mississippi River: A mixed bedrock-alluvial channel, Sedimentology, 58, 1914-1934, doi:10.1111/j.1365-3091.2011.01245.x.

Nittrouer, J. A., J. Shaw, M. P. Lamb, and D. Mohrig (2012a), Spatial and temporal trends for water-flow velocity and bed-material transport in the lower Mississippi River, Geol. Soc. Am. Bull., doi:10.1130/B30497.1, in press.

Nittrouer, J. A., D. Mohrig, and M. A. Allison (2012b), Punctuated sand transport within the lowermost Mississippi River, J. Geophys. Res., doi:10.1029/2011JF002026, in press.
Paola, C. (2000), Sedimentology and sedimentary basins: From turbulence to tectonics, Nature, 405(6783), 123, doi:10.1038/35012122.

Paola, C., G. Parker, R. Seal, S. K. Sinha, J. B. Southard, and P. R. Wilcock (1992), Downstream fining by selective deposition in a laboratory flume, Science, 258(5089), 1757-1760, doi:10.1126/science.258.5089.1757.

Paola, C., R. R. Twilley, D. A. Edmonds, W. Kim, D. Mohrig, G. Parker, E. Viparelli, and V. R. Voller (2011), Natural processes in delta restoration: application to the Mississippi delta, Annu. Rev. Mar. Sci., 3, 67-91, doi:10.1146/annurev-marine-120709-142856.

Parker, G., T. Muto, Y. Akamatsu, W. E. Dietrich, and J. W. Lauer (2008), Unravelling the conundrum of river response to rising sea-level from laboratory to field. Part I: Laboratory experiments, Sedimentology, 55(6), 1643-1655, doi:10.1111/j.1365-3091.2008.00961.x.

Rajaratnam, N. (1976), Turbulent Jets, 302 pp., Elsevier, New York.

Reitz, M. D., D. J. Jerolmack, and J. B. Swenson (2010), Flooding and flow path selection on alluvial fans and deltas, Geophys. Res. Lett., 37, L06401,doi:10.1029/2009GL041985.

Rowland, J. C., W. E. Dietrich, and M. T. Stacey (2010), Morphodynamics of subaqueous levee formation: Insights into river mouth morphologies arising from experiments, J. Geophys. Res., 115, F04007, doi:10.1029/ 2010JF001684.

Slingerland, R., and N. D. Smith (2004), River avulsions and their deposits, Annu. Rev. Earth Planet. Sci., 32, 257-285, doi:10.1146/annurev. earth.32.101802.120201.

Swenson, J. B., C. Paola, L. Pratson, V. R. Voller, and A. B. Murray (2005), Fluvial and marine controls on combined subaerial and subaqueous delta progradation: Morphodynamic modeling of compound-clinoform development, J. Geophys. Res., 110, F02013, doi:10.1029/2004JF000265.

Syvitski, J. P. M., A. J. Kettner, A. Correggiari, and B. W. Nelson (2005), Distributary channels and their impact on sediment dispersal, Mar. Geol., 222-223, 75-94, doi:10.1016/j.margeo.2005.06.030.

Törnqvist, T. E., T. R. Kidder, W. J. Autin, K. van der Borg, A. F. M. de Jong, C. J. W. Klerks, E. M. A. Snijders, J. E. A. Storms, R. L. van Dam, and M. C. Wiemann (1996), A revised chronology for Mississippi river subdeltas, Science, 273(5282), 1693-1696, doi:10.1126/ science.273.5282.1693.

Wright, L. D., and J. M. Coleman (1971), Effluent expansion and interfacial mixing in the presence of a salt wedge, Mississippi River delta, J. Geophys. Res., 76(36), 8649-8661, doi:10.1029/JC076i036p08649.

P. Chatanantavet and M. P. Lamb, Division of Geological and Planetary Sciences, California Institute of Technology, Pasadena, CA 91125, USA. (phairot@caltech.edu)

J. A. Nittrouer, Department of Geology, University of Illinois at UrbanaChampaign, Urbana, IL 61801, USA. 